\title{
Quantitative assessment of vestibular otopathology in otosclerosis: A temporal bone study
}

\author{
Ömer Hizli, MD ${ }^{1,2}$, Serdar Kaya, MD ${ }^{1,3}$, Patricia A. Schachern, BS ${ }^{1}$, Geeyoun Kwon, PhD ${ }^{1}$, \\ Michael M. Paparella, $\mathbf{M D}^{4}$, and Sebahattin Cureoglu, MD ${ }^{1}$ \\ ${ }^{1}$ Department of Otolaryngology - Head and Neck Surgery, University of Minnesota, Minneapolis, \\ Minnesota, USA \\ ${ }^{2}$ Giresun A. Ilhan Ozdemir State Hospital, Giresun, Turkey \\ ${ }^{3}$ Gebze Fatih State Hospital, Gebze, Kocaeli, Turkey \\ ${ }^{4}$ Paparella Ear Head and Neck Institute, Minneapolis, Minnesota, USA
}

\section{Abstract}

Objectives-To determine if peripheral vestibular otopathology is present in human temporal bones with otosclerosis.

\section{Study Design-Comparative human temporal bone study}

Methods-Seventy-four human temporal bones from 46 subjects with otosclerosis (mean age of

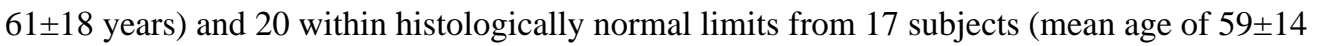
years) were included in this study. Temporal bones with otosclerosis were divided into those with and without endosteal involvement. Using differential interference contrast microscopy at 1008x magnification, type I and type II vestibular hair cell counts were performed on each vestibular sense organ in which the neuroepithelia was oriented perpendicular to the plane of section. The organ-specific cell densities (cells $/ 0.01 \mathrm{~mm}^{2}$ surface area) were compared between the groups with and without endosteal involvement and also compared to counts in the non- otosclerosis control group using Student's t-test.

Results-Mean type I and type II hair cell densities of all vestibular structures in the group with endosteal involvement were significantly lower compared to the group without endosteal involvement. Mean type I and type II hair cell densities of all vestibular structures in the group with endosteal involvement were also significantly lower compared to the control group but were not in the group without endosteal involvement compared to the control group.

Conclusion-Endosteal involvement of otosclerotic foci is associated with damage to the vestibular sensory neuroepithelia that may contribute to the vestibular symptoms in otosclerosis.

Corresponding Author: Sebahattin Cureoglu, MD, Associate Professor, Co-Director, Otopathology Laboratory, Department of Otolaryngology, University of Minnesota, Minneapolis, Minnesota MMC2873, $20016^{\text {th }}$ St SE, LRB 210, Minneapolis, MN 55455, Office: 612-626-9883, cureo003@umn.edu.

Conflict of interest: None

Financial disclosures: None

Level of evidence: NA 


\section{Keywords}

Otosclerosis; histopathology; vertigo; dizziness; vestibule; hair cell

\section{INTRODUCTION}

Otosclerosis, a disease of the otic capsule, was first described by Toynbee in $1860^{1}$ and then later by Politzer in $1893^{2}$. Otosclerosis is an anomaly of bone formation and resorption of the otic capsule with aberrant remodeling. Early lesions of otosclerotic foci appear adjacent to the fissula ante fenestram, the preferred site of the foci just in front of the oval window ${ }^{3-5}$. However, it can also involve other parts of the labyrinthine capsule such as the round window niche, cochlear labyrinth, stapes footplate, posterior of the oval window, internal auditory canal (IAC), around the cochlear and vestibular aqueducts and semicircular canals, causing sensorineural hearing loss and vestibular symptoms in addition to conductive hearing loss ${ }^{6-9}$. Up to $30 \%$ of otosclerosis cases can be presented with vestibular symptoms such as episodes of nonspecific unsteadiness, dizziness, or recurrent attacks of vertigo ${ }^{7}$. The saccule is most likely to be affected by otosclerosis due to its anatomical proximity to the sclerotic foci ${ }^{6}$. No previous studies have investigated the vestibular sensory neuroepithelium in otosclerosis cases. In this study, the effects of otosclerosis on the peripheral vestibular system have been investigated by evaluating and counting type I and type II hair cells of the vestibule using differential interference contrast microscopy (DIC). DIC generates contrast to reach the terminal point of resolution within a limiting field depth to a very narrow range. Furthermore, it provides higher magnification with greater image resolution than conventional light microscopy.

The objectives of this study are as follows:

1. To determine if peripheral vestibular otopathology is present in human temporal bones with otosclerosis.

2. To detect the effects of endosteal involvement of otosclerosis to the vestibular system.

\section{MATERIALS AND METHODS}

\section{Subjects and specimens}

This study examined a total of 94 human temporal bones (HTBs), 74 HTBs from 46 subjects with otosclerosis and 20 HTBs within histologically normal limits from 17 subjects. HTBs with otosclerosis were divided into the two group based on endosteal involvement using conventional light microscopy (Figure 1). Endosteal involvement was defined as the invasion of the otosclerotic foci into the endosteal bone of the labyrinth. Temporal bones from subjects known to have the following conditions that might affect the vestibular system were excluded from this study: head trauma, systemic autoimmune disorders, ototoxic drug use, and any defined otologic diseases other than otosclerosis (e.g., Meniere's disease, active otitis media, labyrinthitis, IAC tumor, etc.). Four subjects had ears both with and without endosteal involvement and were included in both groups, thus the group with endosteal 
involvement consisted of 37 HTBs from 26 subjects while the group without endosteal involvement consisted of 37 HTBs from 24 subjects.

Temporal bones were obtained from the collection at the University of Minnesota (Minneapolis, MN). All of the temporal bones had been removed at autopsy, fixed in formalin solution, decalcified, and embedded in celloidin. Each bone was serially sectioned in the horizontal plane at a thickness of $20 \mu \mathrm{m}$. Every $10^{\text {th }}$ section was stained with hematoxylin and eosin (HE) and mounted on a glass slide for light microscopy. The study was approved by the Institutional Review Board of the University of Minnesota (0206M26181).

\section{Qualitative Histopathologic Assessment}

All HTBs were examined by light microscopy. Each labyrinth was assessed for presence and absence of hydrops. Hydrops was considered to be present if there was distension of the membranous walls of the saccule, utricle or ampullae (vestibular) or of Reissner's membrane (cochlear). Endolymphatic ducts and sacs were also evaluated for involvement of otosclerotic foci. Non-otosclerosis cases within histopathologically normal limits were included in the control group.

\section{Vestibular Hair Cell Density}

Quantitative assessment of the vestibular hair cells was performed as described by Merchant ${ }^{10}$. Accurate assessment is restricted to specimens with minimal postmortem neuroepithelial autolysis and in which the plane of section is perpendicular to the surface of the sensory epithelia ${ }^{10}$. The specimens which demonstrate the microscopic cytology and cell architecture of the vestibular structures, and in which nuclei are adequately preserved to permit a quantitative assessment of vestibular hair cells, were determined as the HTBs with minimal postmortem autolysis and were included in the study. The evaluation of Scarpa's ganglion cells was not performed because many cases did not show any vestibular nerves and Scarpa's ganglion cells in the IACs due to the avulsion of the nerve during the removal process. Using DIC microscopy at x1008 magnification, the cuticular plate and stereociliary bundles of the saccular vestibular hair cells were visualized, and types I and II vestibular hair cells were morphologically and cytological distinguished from each other and from supporting cells using the criteria described by Wersäll ${ }^{11}$ and Merchant ${ }^{10}$ (Figure 2). The type I vestibular hair cells are surrounded by a chalice of afferent nerve fiber, have a flask shape and spherical nucleus. The type II hair cells have a cylindrical shape and many nerve fibers in their bases without a chalice. A cuticular plate and a stereociliary bundle are present in both types I and II vestibular hair cells. Supporting cells have neither a stereociliary bundle nor a cuticular plate and are not innervated.

Vestibular hair cell nuclei were counted in each perpendicularly sectioned maculae and cristae over viewable surface areas of $0.006 \mathrm{~mm}^{2}$. The results were expressed in terms of cell density, the number of hair cells per $0.01 \mathrm{~mm}^{2}$ surface area, in keeping with previous publications ${ }^{12-14}$. Surface area was determined by multiplying the thickness of the section $(20 \mu \mathrm{m})$ by the length of the sensory epithelium where the count was made. The raw hair cell counts were corrected for double counting of cells split between 2 sections using the 
formula of Abercrombie $\left[H_{i}=h_{i} \times t /(t+d)\right.$ where $H_{i}=$ corrected density of hair cells, $h_{i}=$ raw density, $t=$ thickness of section $(20 \mu \mathrm{m})$, and $d=$ mean value of nuclear diameters in 250 vestibular hair cells], which results in correction factors of 0.82 for type I hair cells and 0.87 for type II hair cells 10,15 .

\section{Statistical Analysis}

Results are presented as mean \pm SD. Type I and type II vestibular hair cell densities of each vestibular organ were compared between ears with and without endosteal involvement and also compared to the non-otosclerosis control group. The normal distribution of data from each group was confirmed with the Kolmogorov- Smirnov test $(\mathrm{p}=0.2)$. Statistical comparisons on presence of vertigo and/or dizziness history were performed using Chi squared tests. Statistical comparisons between vestibular hair cell densities were performed using independent t-tests. SPSS 22.0 software for Windows (SPSS Inc., Chicago, IL) was used for analysis of data. A $p$ value less than 0.05 was considered statistically significant.

\section{RESULTS}

Ninety-four HTBs [74 HTBs from 46 subjects with otosclerosis, ages 16-90 years $(61 \pm 18)$ and 20 HTBs from 17 non-otosclerosis subjects within histopathologically normal limits,

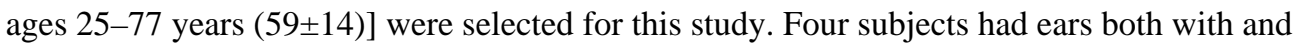
without endosteal involvement and were included in both groups. The group with endosteal involvement consisted of 37 HTBs from 26 subjects, ages 20-90 years (58 19$)$ and the group without endosteal involvement consisted of 37 HTBs from 24 subjects, ages 16-90 years $(65 \pm 17)$.

One of $20(5 \%)$ subjects without any endosteal involvement in both ears had a vertigo history, but 3 of $26(11.5 \%)$ subjects with endosteal involvement in one or more ears had a vertigo and/or dizziness history $\left(\chi^{2}=0.609, \mathrm{p}=0.435\right)$. The overall ratio of vertigo and/or dizziness history for otosclerosis was $4 / 46$ (8.7\%), but this was impossible to confirm, because of limited chart information. No vertigo and/or dizziness history was present in control group. While no subjects had a documented diagnosis of Meniere's disease, 9 of 37 (24.3\%) HTBs without endosteal involvement had cochlear hydrops, 9 of 37 (24.3\%) HTBs with endosteal involvement had cochlear hydrops and 2 of 37 (5.4\%) HTBs with endosteal involvement had saccular hydrops. The endolymphatic ducts and sacs are within normal limits in all HTBs and no otosclerotic foci were seen around and/or nearby the endolymphatic ducts and sacs. Figure 3 shows an example of utricular macula from one subject with endosteal involvement.

Type I and type II vestibular hair cell densities of the superior semicircular canal (SSC), lateral semicircular canal (LSC), utricle, saccule and posterior semicircular canal (PSC) in the group with endosteal involvement were significantly lower compared to the group without (Table 1). Both type I and type II vestibular hair cell densities of SSC, LSC, utricle, saccule and PSC were significantly lower in the group with endosteal involvement (Table 2) but were not in the group without endosteal involvement compared to the control group (Table 3). 


\section{DISCUSSION}

The incidence of vestibular symptoms associated with otosclerosis is known as 10 to $30 \%{ }^{7}$. Vestibular symptoms may be the most distressing and primary symptom in otosclerosis cases ${ }^{16}$. A study performed with 40 cases of otosclerosis suffering from vestibular symptoms revealed that otosclerosis is one of the vestibular disorders most commonly seen, and the degree of hearing loss was associated with vestibular symptoms ${ }^{16}$. In the present study, the mean density of type I hair cells in the saccule, which is more likely to be affected by the otosclerotic foci was significantly lower in cases of otosclerosis with endosteal involvement. The values were similar between the group without endosteal involvement and the control group. Thus involvement of the endosteum by otosclerotic foci might be an important factor for vestibular otopathology in patients with otosclerosis.

It has been hypothesized that toxic metabolites are liberated by the otosclerotic foci into the inner ear fluids and are suggested to be the mechanism of sensorineural hearing loss in otosclerosis ${ }^{17,18}$. Toxic metabolites may affect any part of cochlea and vestibule, thus the inflammatory process caused by toxins released from endosteal otosclerotic foci may damage the sensory neuroepithelium. Recurrent attacks of vertigo, tinnitus, and bilateral mixed hearing loss due to otosclerotic foci invading the endosteal zone have been reported previously 19,20 Otosclerotic inner ear syndrome was described by demonstrating otosclerotic foci in contact with the pars superior by Ghorayeb et al. in patients with otosclerosis and vertigo ${ }^{21}$. In the present study, we demonstrated a decrease in the density of type I and type II hair cells of vestibular organs in cases of otosclerosis with endosteal involvement.

Degeneration of vestibular sensory neuroepithelia in patients with otosclerosis due to involvement of endosteum by otosclerotic foci has some clinical implications. Ocular vestibular evoked myogenic potential (VEMP) abnormalities consistent with utricle pathology and saccular VEMP abnormalities consistent with saccular pathology were found to be more frequent in otosclerosis patients with vestibular symptoms ${ }^{22}$. We can speculate that otosclerosis with endosteal involvement of the otic capsule might be implicated in cases with VEMP abnormalities.

The results of the present study revealed that a significant degeneration of vestibular sensory neuroepithelia is present in otosclerosis with endosteal involvement. However, this study has certain limitations: The limited chart information including medical history and vestibular function tests and mechanical damage from the bone removal. Several cases did not show any vestibular nerves and Scarpa's ganglion cells in the IACs due to the avulsion of the nerve during the removal process, thus the evaluation of Scarpa's ganglion cells was not performed. In summary, the degenerative effect of endosteal involvement to vestibular sensory neuroepithelia is clear but the mechanism of damage needs further investigation.

\section{CONCLUSION}

Endosteal involvement of otosclerotic foci is associated with vestibular hair cell loss that may contribute to the vestibular symptoms in otosclerosis. 


\section{Acknowledgments}

Source of Funding: This project was funded by NIH NIDCD U24 DC011968-01, International Hearing Foundation, Starkey foundation, and 5M Lions International. Authors HIZLI and KAYA awarded the Scientific and Technological Research Council of Turkey (TUBITAK) Scholarship.

\section{References}

1. Toynbee, J. Diseases of the Ear. Philadelphia: Blanchard \& Lea; 1860.

2. Politzer A. Uber primäre erkrankung der knöchernen labyrinthkapsel. Z Ohrenheilkd Kr Luftwege. 1893; 25:309.

3. Derks W, De Groot JA, Raymakers JA, Veldman JE. Fluoride therapy for cochlear otosclerosis? an audiometric and computerized tomography evaluation. Acta Otolaryngol. 2001; 121:174-177. [PubMed: 11349772]

4. Flint, PW.; Cummings, CW. Cummings Otolaryngology Head \& Neck Surgery. Mosby/Elsevier; 2010.

5. Hueb MM, Goycoolea MV, Paparella MM, Oliveira JA. Otosclerosis: the University of Minnesota temporal bone collection. Otolaryngol Head Neck Surg. 1991; 105:396-405. [PubMed: 1945425]

6. Amali A, Mahdi P, Karimi Yazdi A, et al. Saccular function in otosclerosis patients: bone conducted-vestibular evoked myogenic potential analysis. Acta medica Iranica. 2014; 52:111-115. [PubMed: 24659067]

7. Gleeson, M.; Scott-Brown, WG. Scott-Brown's otorhinolaryngology, head and neck surgery. London: Hodder Arnold; 2008.

8. Paparella MM, Chasin WD. Otosclerosis and vertigo. J Laryngol Otol. 1966; 80:511-519. [PubMed: 5934115]

9. Yoon TH, Paparella MM, Schachern PA. Otosclerosis involving the vestibular aqueduct and Menière's disease. Otolaryngol Head Neck Surg. 1990; 103:107-112. [PubMed: 2117717]

10. Merchant SN. A method for quantitative assessment of vestibular otopathology. Laryngoscope. 1999; 109:1560-1569. [PubMed: 10522922]

11. Wersall J. Studies on the structure and innervation of the sensory epithelium of the cristae ampulares in the guinea pig; a light and electron microscopic investigation. Acta Otolaryngol Suppl. 1956; 126:1-85. [PubMed: 13326368]

12. Tsuji K, Velázquez-Villaseñor L, Rauch SD, Glynn RJ, Wall C, Merchant SN. Temporal bone studies of the human peripheral vestibular system. Meniere's disease. Ann Otol Rhinol Laryngol Suppl. 2000; 181:26-31. [PubMed: 10821232]

13. Tsuji K, Velázquez-Villaseñor L, Rauch SD, Glynn RJ, Wall C, Merchant SN. Temporal bone studies of the human peripheral vestibular system. Aminoglycoside ototoxicity. Ann Otol Rhinol Laryngol Suppl. 2000; 181:20-25. [PubMed: 10821231]

14. Merchant SN, Velázquez-Villaseñor L, Tsuji K, Glynn RJ, Wall C, Rauch SD. Temporal bone studies of the human peripheral vestibular system. Normative vestibular hair cell data. Ann Otol Rhinol Laryngol Suppl. 2000; 181:3-13. [PubMed: 10821229]

15. Abercrombie M. Estimation of nuclear population from microtome sections. The Anatomical Record. 1946; 94:239-247. [PubMed: 21015608]

16. Eza-Nuñez P, Manrique-Rodriguez M, Perez-Fernandez N. Otosclerosis among patients with dizziness. Rev Laryngol Otol Rhinol (Bord). 2010; 131:199-206. [PubMed: 21488576]

17. Nager GT. Histopathology of otosclerosis. Archives of otolaryngology (Chicago, Ill : 1960). 1969; 89:341-363.

18. De Souza, C.; Glasscock, ME. Otosclerosis and stapedectomy : diagnosis, management, and complications. New York: Thieme; 2004.

19. Igarashi M, Jerger S, O-Uchi T, Alford BR. Fluctuating hearing loss and recurrent vertigo in otosclerosis. An audiologic and temporal bone study. Arch Otorhinolaryngol. 1982; 236:161-171. [PubMed: 7150081]

20. Hayashi H, Onerci O, Paparella MM. Cochlear otosclerosis. Otol Neurotol. 2006; 27:905-906. [PubMed: 16885782] 
21. Ghorayeb BY, Linthicum FH. Otosclerotic inner ear syndrome. Ann Otol Rhinol Laryngol. 1978; 87:85-90. [PubMed: 623424]

22. Lin K-Y, Young Y-H. Role of ocular VEMP test in assessing the occurrence of vertigo in otosclerosis patients. Clin Neurophysiol. 2015; 126:187-193. [PubMed: 24835794] 


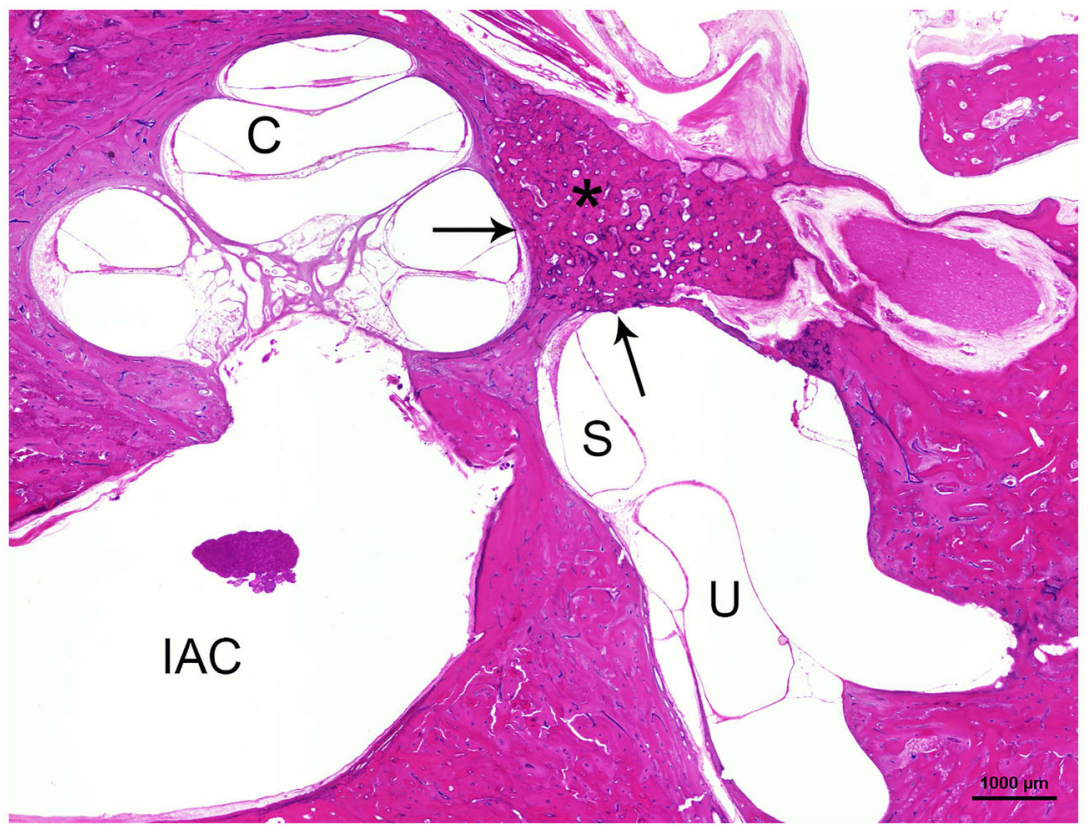

Figure 1.

Otosclerotic foci (*) involving the endosteum. C: cochlea; S: Saccule; U: Utricle; IAC:

Internal auditory canal; arrows indicate otosclerotic foci involving the cochlea and vestibule. 

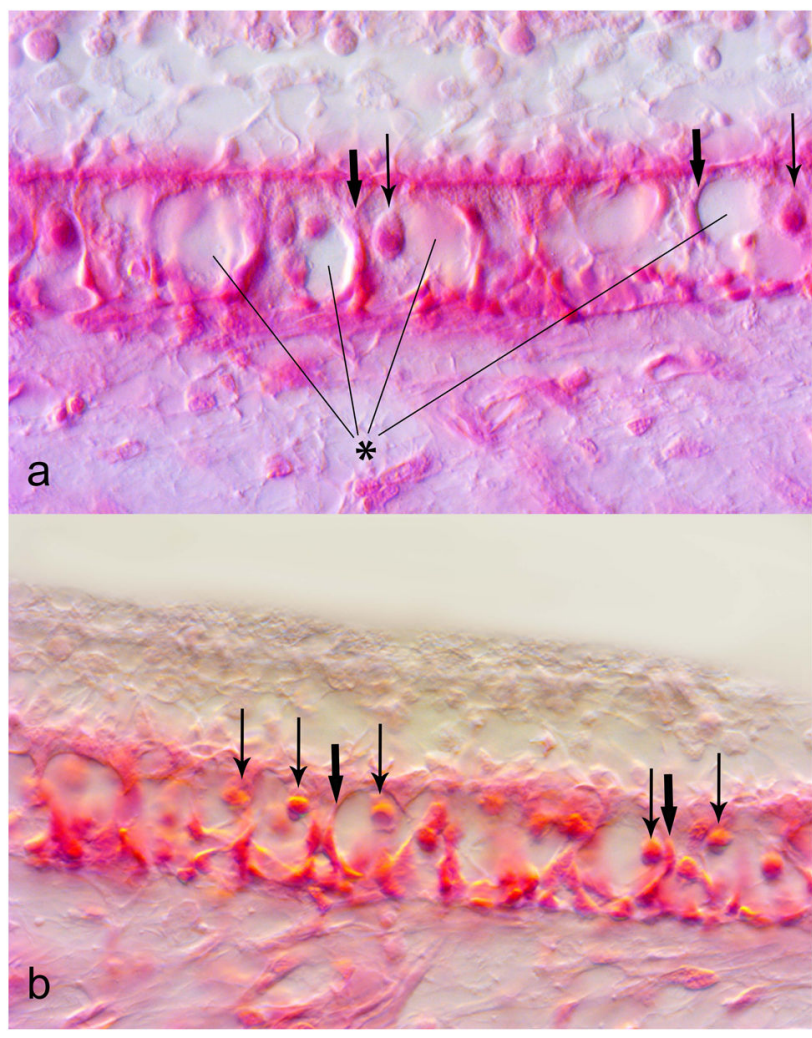

Figure 2.

Differential interference contrast photomicrograph of utricular macula of two different cases. (a) A case with endosteal involvement. (b) A Case without endosteal involvement. Thin arrows: Type I Vestibular Hair Cells; Thick arrows: Type II Vestibular Hair Cells; * shows areas of hair cell loss. 


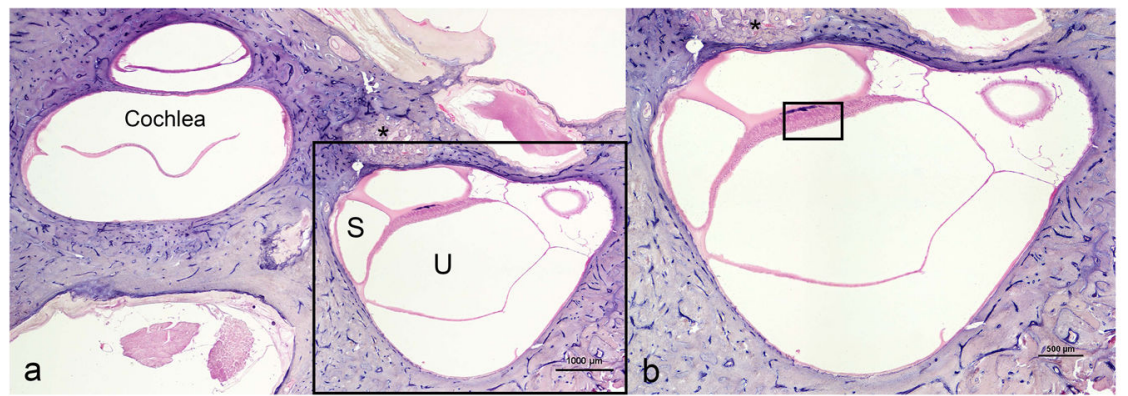

Figure 3.

Light photomicrograph of the temporal bone from a 78-year-old man with otosclerosis $(*)$ involving the endosteum. S: Saccule; U: Utricle. (a) Lower magnification image. (b) Magnified view of boxed area. Boxed area in (b) corresponds to Fig 2a. 
Table 1

Mean Type I and II vestibular hair cell densities of two groups compared each other.

\begin{tabular}{|l|c|c|c|}
\hline Vestibular structure & Group with endosteal involvement & Group without endosteal involvement & $\boldsymbol{p}$ value \\
\hline SSC Type I $^{*}$ & $43.98 \pm 14.14$ & $58.82 \pm 9.64$ & 0.025 \\
\hline SSC Type II $^{*}$ & $22.89 \pm 6.87$ & $35.53 \pm 5.63$ & 0.001 \\
\hline LSC Type I $^{*}$ & $41.73 \pm 10.83$ & $56 \pm 9.69$ & $<0.001$ \\
\hline LSC Type II $^{*}$ & $22.46 \pm 7.21$ & $34.10 \pm 6.93$ & $<0.001$ \\
\hline Utricle Type I $^{*}$ & $43.90 \pm 11.42$ & $53.43 \pm 8.72$ & $<0.001$ \\
\hline Utricle Type II $^{*}$ & $25.47 \pm 5.89$ & $33.87 \pm 6.28$ & $<0.001$ \\
\hline Saccule Type I* & $43.45 \pm 11.64$ & $54.15 \pm 9.57$ & $<0.001$ \\
\hline Saccule Type II & $24.97 \pm 7.92$ & $36.85 \pm 7.15$ & $<0.001$ \\
\hline PSC Type I* & $42.45 \pm 12.42$ & $53.31 \pm 6.21$ & 0.019 \\
\hline PSC Type II & $25.73 \pm 7.03$ & $35.21 \pm 5.85$ & $<0.001$ \\
\hline
\end{tabular}

* ${ }^{*} 0.01 \mathrm{~mm}^{2}$, SSC indicates superior semicircular canal; LSC: lateral semicircular canal; PSC: posterior semicircular canal. 
Table 2

Mean Type I and II vestibular hair cell densities of the group with endosteal involvement compared to the control group.

\begin{tabular}{|l|c|c|c|}
\hline Vestibular structure & Group with endosteal involvement & Control Group & $\boldsymbol{p}$ value \\
\hline SSC Type I $^{*}$ & $43.98 \pm 14.14$ & $57.57 \pm 6.21$ & 0.02 \\
\hline SSC Type II $^{*}$ & $22.89 \pm 6.87$ & $31.17 \pm 4.77$ & 0.008 \\
\hline LSC Type I $^{*}$ & $41.73 \pm 10.83$ & $58.31 \pm 5.42$ & $<0.001$ \\
\hline LSC Type II $^{*}$ & $22.46 \pm 7.21$ & $35.6 \pm 7.78$ & $<0.001$ \\
\hline Utricle Type I $^{*}$ & $43.90 \pm 11.42$ & $56.43 \pm 6.62$ & $<0.001$ \\
\hline Utricle Type II $^{*}$ & $25.47 \pm 5.89$ & $37.44 \pm 8.71$ & $<0.001$ \\
\hline Saccule Type I & $43.45 \pm 11.64$ & $56.64 \pm 6.71$ & $<0.001$ \\
\hline Saccule Type II & $24.97 \pm 7.92$ & $36.41 \pm 9.23$ & $<0.001$ \\
\hline PSC Type I & $42.45 \pm 12.42$ & $55.12 \pm 7.63$ & 0.01 \\
\hline PSC Type II $^{*}$ & $25.73 \pm 7.03$ & $35.28 \pm 6.52$ & 0.002 \\
\hline
\end{tabular}

per $0.01 \mathrm{~mm}^{2}$, SSC indicates superior semicircular canal; LSC: lateral semicircular canal; PSC: posterior semicircular canal. 
Table 3

Mean type I and II vestibular hair cell densities in the group without endosteal involvement compared to the control group.

\begin{tabular}{|l|c|c|c|}
\hline Vestibular structure & Group without endosteal involvement & Control group & $\boldsymbol{p}$ value \\
\hline SSC Type I $^{*}$ & $58.82 \pm 9.64$ & $57.57 \pm 6.21$ & 0.247 \\
\hline SSC Type II $^{*}$ & $35.53 \pm 5.63$ & $31.17 \pm 4.77$ & 0.606 \\
\hline LSC Type I $^{*}$ & $56 \pm 9.69$ & $58.31 \pm 5.42$ & 0.370 \\
\hline LSC Type II $^{*}$ & $34.10 \pm 6.93$ & $35.6 \pm 7.78$ & 0.516 \\
\hline Utricle Type I $^{*}$ & $53.43 \pm 8.72$ & $56.43 \pm 6.62$ & 0.219 \\
\hline Utricle Type II $^{*}$ & $33.87 \pm 6.28$ & $37.44 \pm 8.71$ & 0.103 \\
\hline Saccule Type I & $54.15 \pm 9.57$ & $56.64 \pm 6.71$ & 0.340 \\
\hline Saccule Type II & $36.85 \pm 7.15$ & $36.41 \pm 9.23$ & 0.855 \\
\hline PSC Type I & $53.31 \pm 6.21$ & $55.12 \pm 7.63$ & 0.548 \\
\hline PSC Type II & $35.21 \pm 5.85$ & $35.28 \pm 6.52$ & 0.981 \\
\hline
\end{tabular}

per $0.01 \mathrm{~mm}^{2}$, SSC indicates superior semicircular canal; LSC: lateral semicircular canal; PSC: posterior semicircular canal. 